\title{
HOSPITAL IN THE HOME NURSES' RECOGNITION AND RESPONSE TO CLINICAL DETERIORATION
}

\section{RUNNING HEAD: RECOGNITION AND RESPONSE TO DETERIORATION IN} HITH
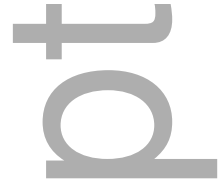

AUTHORS

Name:

Qualifications:

Affiliation:

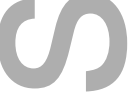

Address:

Email:

Telephone:

Name:

Qualifications:

Affiliation:

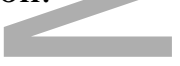

Address:

Email:

Telephone

Name:

Qualifications:

Affiliation:

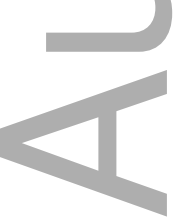

Address:

Email:

This is the author manuscript accepted for publication and has undergone full peer review but has not been through the copyediting, typesetting, pagination and proofreading process, which may lead to differences between this version and the Version of Record. Please cite this article as doi: $10.1111 /$ jocn.14076

This article is protected by copyright. All rights reserved
Erika Gray

$R N$, GDipNurs(CritCare), $M N$

School of Nursing and Midwifery, Deakin University

Practice Development Unit, Eastern Health

c/- Deakin University, Geelong, Victoria, Australia, 3125.

erika.gray@easternhealth.org,au

+61423100619

Professor Judy Currey

$R N P h D$

School of Nursing and Midwifery and Centre for Quality and Patient Safety Research, Deakin University

c/- Deakin University, Geelong, Victoria, Australia, 3125.

judy.currey@deakin.edu.au

+61392446122

Professor Julie Considine

$R N$ PhD

School of Nursing and Midwifery and Centre for Quality and Patient Safety Research, Deakin University

Eastern Health - Deakin University Nursing \& Midwifery

Research Centre

c/- Deakin University, Geelong, Victoria, Australia, 3125

julie.considine@deakin.edu.au 
Telephone:

+61392446127

\section{AUTHORSHIP}

EG, JCo and JCu conceived and designed the study. EG and JCo developed the study protocol and undertook article screening and selection. EG, JCo and JCu analysed the data and prepared and approved the manuscript.

\section{FUNDING}

This study was generously supported by scholarships from the Nurses Memorial Centre, The Prince Henry's Affiliates and Eastern Health.

\section{CONFLICT OF INTEREST}

No conflict of interest

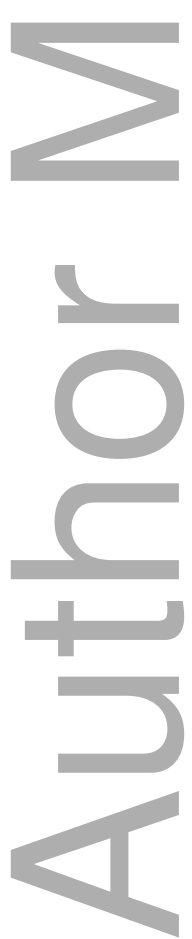


MRS. ERIKA GRAY (Orcid ID : 0000-0002-4811-1506)

PROF. JULIE CONSIDINE (Orcid ID : 0000-0003-3801-2456)

\section{$+\frac{1}{10}$ \\ Article type :Original Article \\ - \\ Hospital in the Home Nurses' Recognition and Response to Clinical Deterioration}

\section{ABSTRACT \\ Aims and objectives}

To obtain an understanding of how HITH (Hospital in the Home) nurses recognise and respond to clinical deterioration in patients receiving care at home or in their usual place of residence.

\section{Background}

Recognising and responding to clinical deterioration is an international safety priority and a key nursing responsibility. Despite an increase in care delivery in home environments, how HITH nurses recognise and respond to clinical deterioration is not yet fully understood.

\section{Design}

A prospective, descriptive exploratory design was used. A survey containing questions related to participant characteristics and 10 patient scenarios was used to collect data from 47 nurses employed in the HITH units of three major health services in Melbourne, Australia. The 10 scenarios reflected typical HITH patients and included medical history and clinical assessment findings (respiratory rate, oxygen saturation, heart rate, blood pressure, temperature, conscious state and pain score).

\section{Results}

The three major findings from this study were that: i) nurse and patient characteristics influenced HITH nurses' assessment decisions; ii) the cues used by HITH nurses to recognise clinical deterioration varied according to the clinical context; and iii) although HITH nurses work in an autonomous role, they engage in collaborative practice when responding to clinical deterioration. 


\section{Conclusion}

Hospital in the Home nurses play a fundamental role in patient assessment, and the context in which they recognise and respond to deterioration is markedly different to that of hospital nurses.

\section{Relevance to clinical practice}

The assessment, measurement and interpretation of clinical data are a nursing responsibility that is crucial to early recognition and response to clinical deterioration. The capacity of HITH services to care for increasing numbers of patients in their home environment, and to promptly recognise and respond to clinical deterioration should it occur, is fundamental to safety within the healthcare system. Hospital in the Home nurses are integral to a sustainable health care system that is responsive to dynamic changes in public health policies, and meets the health care needs of the community.

\section{Summary box - What does this paper contribute to the wider community?}

- This study provides an understanding of the role HITH nurses have in the assessment of their patients, and in the recognition and response to clinical deterioration

- This is the first known Australian study of HITH nurses recognition and response to clinical deterioration.

- A better understanding of how HITH nurses recognise and appropriately respond to clinical deterioration will inform clinical practice, organisational systems and guidance documents related to recognising and responding to clinical deterioration in non-hospital settings.

- Understanding nurses' decision making in the HITH setting may further inform future healthcare reforms to enable the delivery of acute care in home environments as an inpatient hospital admission.

Keywords: nursing, hospital in the home nursing, patient assessment, risk assessment, home care services, home nursing, clinical deterioration

\section{Hospital in the Home Nurses' Recognition and Response to Clinical Deterioration}




\section{INTRODUCTION}

Contemporary health care is changing to meet increasing healthcare demands. The home as a location of care can reduce hospital admissions or decrease the length of in-hospital stay (Caplan \& Boxall 2012). The Hospital in the Home (HITH) service was first introduced in Australia over 20 years ago (Schwab 1994). Patients cared for by HITH nurses are considered hospital in-patients, and are usually visited once or twice each day. Patients whose conditions deteriorate in most acute hospital settings will trigger a Rapid Response System review in line with local and national policies and procedures (Australian Commission for the Safety and Quality Health Care 2012, Eastern Health 2013, 2016, Epworth Healthcare 2015, Monash Health 2015). Despite being cared for at home, HITH patients, as hospital in-patients, are also entitled to receive prompt and appropriate recognition of and response to clinical deterioration according to international standards (National Institute for Health and Care Excellence 2017, National Health Service England 2017, Institute for Healthcare Improvement 2017, American Heart Association 2015). There are significant gaps in the published literature pertaining to what is currently known about how nurses recognise and respond to clinical deterioration in the HITH setting. For the purpose of this study, clinical deterioration was defined as a decline in physical or mental state posing danger to a patient in the healthcare setting (ACSQHC 2012).

\section{Background}

Recognising and responding to clinical deterioration is an international safety priority in healthcare. Failure to recognise and respond promptly to clinical deterioration can result in patient morbidity and death (Kelly et al. 2014). Early recognition and response to clinical deterioration significantly improves patient outcomes (Buist et al. 2002, Bellomo et al. 2003, Jones 2014). Many countries around the world make clear recommendation about systems and processes for recognition and response to deterioration that typically include measurement and interpretation of patient assessment data, and if abnormalities are noted, escalation of care (National Institute for Health and Care Excellence 2017, National Health Service England 2017, Institute for Healthcare Improvement 2017, American Heart Association 2017).

Nursing scope of practice is dependent on the level of nurses' education, training and competence to carry out certain tasks and roles, and is governed by the organisational policies 
of their employer (Nursing and Midwifery Board of Australia, 2015). Hospital in the Home nurses are on the frontline of patient care that involves both patient assessment and management of specific conditions in a home environment. In order to enable comprehensive assessment, HITH nurses in Australia are usually equipped with sphygmomanometers, stethoscopes, thermometers and pulse oximeters. Depending on the patient's clinical condition, HITH nurses typically visit the patient's home once or twice daily.

\section{Aim}

The aim of this study was to obtain an understanding of how HITH nurses recognise and respond to clinical deterioration in patients receiving care at home or in their usual place of residence. The study addressed the following research questions:

i) What cues do HITH nurses use to recognise clinical deterioration?

ii) What cues do HITH nurses rate as most and least important in recognising clinical deterioration?

iii) What actions do HITH nurses' take if clinical deterioration is recognised?

\section{METHODS}

\section{Design}

This study was conducted using a prospective, descriptive exploratory design. Purposive sampling was used to select participants from three major metropolitan HITH services in Melbourne, Australia. Approval for this study was sought and granted by the Human Research and Ethics Committees at the three study sites (15236L, LR226-15 and LR01/2016), and Deakin University (2015-139).

\section{Setting}

There are in excess of 45 HITH services across metropolitan and rural Victoria, Australia. This study was carried out at the HITH units of three major metropolitan health services in Melbourne, Victoria; the details of these settings are shown in Table 1.

**Table 1 here

These services were selected because they were the two largest public health services (health services A and B) and the largest private health service (health service C) in Victoria. 
Typical service delivery for these HITH services is one to two visits per patient per day. The HITH nurses in these services carry the following monitoring equipment:

sphygmomanometer, stethoscope, thermometer pulse oximeter and glucometer.

\section{Participants}

A total of 73 nurses employed by these three Melbourne HITH services were invited to participate in this study. All participants were employed as registered nurses (RN) Grade 3B or above. Grade 3B is the classification for RNs working in HITH and reflects the required nursing experience and skill level appropriate for nurses practicing autonomously within the HITH setting (Nurses \& Midwives Victorian Public Health Sector Enterprise Agreement, 2016). In Australia, newly graduated RNs are Grade 2, Year 1 and the majority of clinical RNs are employed as Grade 2, Years 2 to 10 (Australian Nursing \& Midwifery Federation, 2016). Each HITH unit is led by a nurse unit manager (NUM) who is responsible for the operational function of the unit, assisted by a team of associate nurse unit managers (ANUMs). In the survey the positions of NUM and ANUM were merged to ensure anonymity as there is usually only one NUM per HITH service. A total of 47 nurses answered the survey questions giving a response rate of $64.4 \%$.

\section{Data collection}

A survey was used to collect the study data. The survey included 10 patient scenarios, reflecting common profiles of HITH patients with varying degrees of clinical deterioration. The patient scenarios were based on the researcher's (EG) experience as a HITH nurse. Each scenario was written using a consistent format describing patient details (age, gender, living arrangements, past medical history, medications, allergies, and current clinical condition), and a series of clinical assessment findings (respiratory rate, oxygen saturation, heart rate, blood pressure, temperature, conscious state and pain score). A summary of scenario content is presented in Table 2 .

** Table 2 here

Participants were asked to rate the importance of each vital sign parameter and clinical assessment finding using a 5 -point Likert scale $(1=$ not important to $5=$ very important $)$. 
The participants were then asked to state three other features of the patient scenario that they thought were important in recognising clinical deterioration. The additional features were different in each scenario, and could be physical, environmental or situational observations. Participants were asked to nominate the most appropriate action on completion of the visit for each scenario from a range of multiple-choice answers. The actions ranged from 'revisit as planned with no escalation of care required' to 'calling an ambulance'. Participants were also able to select 'other' and add free text comments to allow for differences in HITH services' governance, policies and clinical practice guidelines.

To ensure the reliability and validity of the survey, an expert advisory panel was used. Reliability refers to the consistency of material data measured in a study (Polit \& Beck 2012), and to the consistency of participants' understanding of the survey questions (Parahoo 2006). Validity is the degree to which the survey addressed the questions being asked (Bannigan \& Watson 2009). Face and content validity were established using an expert advisory panel. Members of the expert advisory panel were seven senior nurses with HITH, community and emergency nursing backgrounds from health services in Victoria and South Australia. Their years of experience varied from 6 to 36 years and they had a range of 2 to $>5$ years in HITH or community based nursing. The panel were asked to review the survey and comment on the ease of completion, clarity of instructions and whether the clinical content was representative of HITH nursing practice, and the patient data that it intended to measure. Following the pilot process, minor modifications were made in response to the comments made by the panel. The finalised survey was sent out anonymously to participants, with an option to complete the survey electronically or on paper. The majority of participants $85 \%$ $(n=40)$ elected to use the electronic version.

\section{Data analysis}

Data were analysed using IBM SPSS Statistics (IBM Corp 2015). Descriptive statistics (frequencies, means, and standard deviations) were used to summarise the study data (Brace et al. 2012). Thematic analysis (Braun \& Clarke 2006) was used to analyse the free text comments. The researcher (EG) analysed the free text comments to identify key words and themes (Table 6). Identified themes were reviewed by the research team to ensure accurate representation of participant comments. 


\section{RESULTS}

\section{Participant Characteristics}

A total of 47 nurses answered the survey questions, providing an overall response rate of $64.4 \%$. The majority of participants held a Bachelor of Nursing degree $(66 \%, \mathrm{n}=31)$, and $46.8 \%(n=22)$ of participants had completed postgraduate studies.

Participant characteristics and data summarising participants' qualifications and educational preparation are shown in Table 3.

**Table 3 here

\section{Recognition of clinical deterioration}

The top three vital signs considered as very important indicators for clinical deterioration in all 10 of the scenarios were: pulse rate $(60.5 \%, n=229)$, pain score $(60 \%, n=227)$ and respiratory rate $(59.5 \%, \mathrm{n}=225)$. A summary of all the cues rated as very important indicators of clinical deterioration for each scenario, ranked in descending order, is shown in Table 4.

**Table 4 here

\section{Response to clinical deterioration}

The two most common responses to signs of clinical deterioration in HITH patients were: consultation with the treating medical team by phone $(35.1 \%, \mathrm{n}=133)$ and urgent face-to-face review in clinic in-hours $(25.9 \%, \mathrm{n}=98)$. A summary of all the responses to signs of clinical deterioration for each scenario is shown in Table 5.

** Table 5 here

The choice of 'other' as an optional answer to this question in the survey invited participants to provide free text comments. A summary of the free text comments is shown in Table 6 .

** Table 6 here

\section{DISCUSSION}

The major findings from this study were: i) nurse and patient characteristics influenced HITH nurses' assessment decisions; ii) the cues used by HITH nurses to recognise clinical deterioration varied according to the clinical context; and iii) although HITH nurses work in 
an autonomous role, they engage in collaborative practice when responding to clinical deterioration.

Educational preparation, years of experience and familiarity in a specialty (or area of practice) strongly influence nurses' assessment skills, clinical judgments and decisionmaking (Donizetti Trevisan et al. 2013, Felton \& Royal 2015, Morgan \& Georges 2015, Marques dos Santos et al. 2016, Saunders 2016). Higher levels of education and greater experience improve the overall quality of nursing assessment and decision-making (Liaw et al. 2011, Rahman et al. 2015) so are therefore desirable atributes for nurses working in autonomous roles such as HITH. Furthermore, nurses' educational preparation has a direct impact on patient outcomes. Numerous studies have shown that when the proportion of degree-prepared nurses increases, patient mortality and adverse events decrease (Aiken et al. 2003, Aiken et a1. 2014, Cho et al. 2014, Gkantaras et al. 2016). Both formal and informal programs of ongoing postgraduate nurse education improve assessment skills, and ultimately result in safer patient care outcomes (Liaw et al. 2011, Owen et al. 2014). In this study, participants had a median number of 20 years' experience as registered nurses; 4 years' experience working in home based care settings and worked a median of 56 hours per fortnight. Two thirds of participants were Bachelor prepared and almost half had postgraduate qualifications. These findings show that HITH nurses are well educated and highly experienced. As this study did not examine decision accuracy as a function of education or experience, further research is required to objectively determine the characteristics of HITH nurses that optimise patient outcomes.

The cues used by HITH nurses to recognise clinical deterioration varied according to the clinical context. The top three vital signs considered as very important indicators for clinical deterioration were: pulse rate, pain score and respiratory rate. Pulse rate was most frequently rated as very important across all scenarios, with very important rated in $60.5 \%$ of the scenarios studied. Changes to pulse rate are considered important as predictors of clinical deterioration (Cuthbertson et al. 2007), especially in combination with other abnormal vital signs (Cretikos et al. 2007, Considine et al. 2009).

Pain score was rated as very important in $60.0 \%$ of the scenarios studied. Pain that is increased or reported as a new symptom is considered a warning sign in clinical deterioration (Purser et al. 2014, Shatkar et al. 2014). Pain can be a significant problem for patients in HITH programs, and pain management in home care environments has been reported as 
below hospital standard (Duke et al. 2012), especially in the event of less than optimal pain management discharge planning. Pain was rated as the most important sign in three of the 10 scenarios, featured as second most important in two scenarios, and was rated as important in more than $33.3 \%$ of the other scenarios. Pain score was considered the most important cue in Scenarios 7,8 and 10 in which all of the patients reported pain. Participant comments questioned whether the pain was new or increased, requested further assessment, and commented upon the appropriateness of the prescribed analgesia; all suggesting critical thinking at a contextual level about the patient scenarios. The consideration of additional cues, given the nurses' comments, is indicative of HITH nurses' contextual awareness in seeking further information before making their decision.

Respiratory rate was rated as very important in $59.5 \%$ of scenarios studied. Changes to respiratory rate, in particular tachypnoea, are a clear indicator of critical illness and of adverse events such as intensive care admission, cardiac arrest and death (Considine 2005, Cretikos et al. 2007, Cuthbertson et al. 2007, Cretikos et al. 2008, Farley et al. 2010). Vital signs found to be within an abnormal range, but not within MET call criteria have preceded adverse events (Considine et al. 2016). In this study, tachypnoea warranting a clinical review occurred in three scenarios (Scenarios 2, 3 and 9). A respiratory rate greater than 24 breaths per minute is an important predictor of clinical deterioration because changes imply ventilation abnormalities at a cellular level that are normally corrected by increased respiratory rate and tidal volume (Cretikos et al. 2008). The responses given for these scenarios were appropriate, as the respiratory rate values were aligned with hospital policies for escalation of care (Eastern Health 2013, 2016, Epworth Healthcare 2015, Monash Health 2015).

Oxygen saturation was rated very important in only $46.2 \%$ of scenarios and was one of the least important cues across most scenarios. These findings suggest that HITH nurses placed greater value on respiratory rate than on oxygen saturation as an indicator of clinical deterioration. It is a positive finding that HITH RNs are identifying signs of deterioration based on respiratory rate rather than oxygen saturation; given respiratory rate is the most sensitive and specific vital sign indicator of serious illness (Considine 2005, Cretikos et al. 2007, Cuthbertson et al. 2007, Cretikos et al. 2008, Cioffi et al. 2009, Farley et al. 2010). 
Nurses in HITH assess patients and make decisions that are individually contextualised, and aligned to local, national and international guidelines for recognising and responding to clinical deterioration (Australian Commission for the Safety and Quality Health Care 2012, Eastern Health 2013, 2016, Epworth Healthcare 2015, Monash Health 2015, National Institute for Health and Care Excellence 2017, National Health Service England 2017, Institute for Healthcare Improvement 2017, American Heart Association 2015). In HITH nursing care, nurses carry out physical assessments of their patients at each visit to inform their plans of care and deliver patient care in collaboration with the health care team. In most cases the care progresses without change until the next scheduled visit or medical review. For the scenarios that included signs of suspected clinical deterioration, other responses were chosen. Consulting with the medical team leader was the most common overall response (35.1\%; $\mathrm{n}=133$ ) to signs of clinical deterioration in HITH patients. All four participants who commented requested more information about the patient, with three stating they would consult the medical team with this further information. The next most frequent response selected by participants was for urgent review in the clinic (in-hours); this option was selected in $25.9 \%(\mathrm{n}=98)$ of scenarios. The option to escalate care by contacting the medical team leader was a common theme for the scenarios where 'other' was the chosen course of action.

Nurses are expected to accurately convey any changes or concerns for their patients to the appropriate medical team. Nurses in HITH must decide whether a patient requires further assessment by phone, by additional nurse visit, or by face-to-face medical review or readmission to hospital. If HITH patients require more frequent assessment on a daily basis, the only option currently available is hospital readmission. Opportunities exist in the HITH setting for development of technology to provide alternative modes for patient assessment, such as remote electronic monitoring and phone or electronic visual consultation. Integration of technology by nurses in acute hospitals is rapidly evolving (Chu \& Wilder 2014, Cook et al. 2015, Khan et al. 2016). Indeed, integration of technology to enable remote vital sign monitoring or electronic face to face review in home care environments warrants future consideration. The results of this study provide reassurance that HITH nurses follow current hospital guidelines for recognition of clinical deterioration and escalation of care, which in Australia are based on Standard 9 of the National Safety and Quality Heath Service (NSQHS) standards (ACSQHS, 2012,Eastern Health 2013, 2016, Epworth Healthcare 2015, Monash Health 2015). 


\section{LIMITATIONS}

There are a number of limitations that should be considered when interpreting the study findings. First, HITH nurses' decisions were examined using hypothetical scenarios rather than real patients, so the generalisability of the study results to real clinical practice is not claimed. However, the scenarios were based on usual HITH cases and underwent a rigorous review process to ensure reliability and validity. Further, the use of scenarios enabled comparison of responses from a number of HITH nurses to the same data. Second, participants were self-selecting; therefore there may have been sampling bias as the characteristics of non-participants are unknown. However, participants were from the HITH services of Victoria's largest public and private health services and the response rate of $64.4 \%$ is considered acceptable (Fincham 2008).

\section{CONCLUSION}

This is the first known Australian study of HITH nurses' recognition and response to signs of clinical deterioration in patients who are technically in-patients, but are not receiving care within the hospital. It is clear that HITH nurses have a fundamental role in patient assessment, but the context in which they recognise and respond to deterioration is markedly different to that of hospital-based nurses. Study findings suggest that nurses in HITH appropriately recognise and respond to signs of clinical deterioration, consider the context of the patient and the patient's environment in their decisions; and practice according to local, national and international guidelines and the governance systems of the health service in which they are employed. In the future, clinical decision-making skills already enhanced by the experience and educational preparation of HITH nurses could be complemented further by innovations in technology. The capacity of HITH services to care for increasing numbers of patients in their home environments, and for prompt recognition and response to clinical deterioration should it occur, is fundamental to building capability within the healthcare system. Hospital in the Home nurses are integral to a sustainable health care system that must be responsive to dynamic changes in public health policies, and meet the health care needs of the community. 


\section{FUNDING}

This study was generously supported by scholarships from the Nurses Memorial Centre, The Prince Henry’s Affiliates and Eastern Health.

\section{REFERENCES}

Aiken, L. H., Clarke, S. P., Cheung, R. B., Sloane, D. M., \& Silber, J. H. (2003). Educational levels of hospital nurses and surgical patient mortality. JAMA, The Journal of the American Medical Association 290, 1617-1623.

Aiken, L. H., Sloane, D. M., Bruyneel, L., Van den Heede, K., Griffiths, P., Busse, R., ...Sermeus, W. (2014). Articles: Nurse staffing and education and hospital mortality in nine European countries: a retrospective observational study. The Lancet 383, 1824-1830.

American Heart Association (2017). Guidelines for Cardiopulmonary Resuscitation and Emergency Cardiovascular Care. Retrieved 1 September 2017 from https://eccguidelines.heart.org/index.php/circulation/cpr-ecc-guidelines-2/part-4systems-of-care-and-continuous-quality-improvement/

Australian Commission on Safety and Quality in Healthcare (2012). National safety and quality health service standards. Retrieved 1 September 2017 from http://www.safetyandquality.gov.au/wp-content/uploads/2011/09/NSQHS-StandardsSept-2012.pdf

Australian Nursing and Midwifery Federation (2012-2016). Nurses and midwives (Victorian Public Health Sector) (Single Interest Employers) enterprise agreement. Retrieved 1 September 2017 from http://admin.anfvic.asn.au/multiversions/42273/FileName/2012_2016_general_EBA.p df

Bannigan, K., \& Watson, R. (2009). Reliability and validity in a nutshell. Journal of Clinical Nursing 18, 3237-3243.

Bellomo, R., Goldsmith, D., Uchino, S., Buckmaster, J., Hart, G. K., Opdam, H., ...Gutteridge, G. (2003). A prospective before-and-after trial of a medical emergency team. Medical Journal of Australia 179, 283-287.

Brace. N., Kemp, R., \& Snelgar, R. (2012). SPSS for psychologists. (5th ed.) Basingstoke, UK: Palgrave Macmillan.

Braun, V., \& Clarke, V. (2006). Using thematic analysis in psychology, Qualitative Research in Psychology 3, no. 2, 77-101. 
Buist, M. D., Moore, G. E., Bernard, S. A., Waxman, B. P., Anderson, J. N., \& Nguyen, T. V. (2002). Effects of a medical emergency team on reduction of incidence of and mortality from unexpected cardiac arrests in hospital: preliminary study. BMJ: British Medical Journal (International Edition) 324, 387-390.

Caplan, G., \& Boxall, A-M. (2012). Is Hospital in the Home as safe and effective as inpatient care? AHHA, Canberra.

Cho, E., Sloane, D. M., Kim, E-Y., Kim, S., Choi ,M., Yoo, I. Y., ...Aiken, L. H. (2014). Effects of nurse staffing, work environments, and education on patient mortality: An observational study. International Journal Of Nursing Studies 52, 535-542.

Chu, A., \& Wilder, V. (2014) Current Technology Trends: Wearable Medical Devices. New YorkFamily Medicine News, 8-10.

Cioffi, Conway, R., Everist, L., Scott, J., \& Senior, J. (2009). 'Patients of concern' to nurses in acute care settings: a descriptive study. Australian Critical Care 22, 178-186.

Considine, J. (2005). The role of nurses in preventing adverse events related to respiratory dysfunction: literature review. Journal of Advanced Nursing 49, 624-633.

Considine, J., Thomas, S., \& Potter, R., (2009). Predictors of critical care admission in emergency department patients triaged as low to moderate urgency. Journal of Advanced Nursing 65, 818-827.

Considine. J., Trotter, C., \& Currey. J, (2016). Nurses' documentation of physiological observations in three acute care settings. Journal of Clinical Nursing 25, 134-143 $110 \mathrm{p}$.

Cook. A.J., Gargiulo, G. D., Lehmann, T., \& Hamilton, T. J. (2015). Open platform, eightchannel, portable bio-potential and activity data logger for wearable medical device development. Electronics Letters 51, 1641-1642.

Cretikos. M., Bellomo, R., Hillman, K., Chen, J., Finfer, S., \& Flabouris, A. (2008). Respiratory rate: the neglected vital sign. Med J Aust 188, 657-659.

Cretikos, M., Chen, J., Hillman, K., Bellomo, R., Finfer, S., \& Flabouris, A. (2007). Clinical paper: The objective medical emergency team activation criteria: A case-control study. Resuscitation 73, 62-72.

Cuthbertson, B. H., Boroujerdi, M., McKie L., Aucott, L., \& Prescott, G. (2007). Can physiological variables and early warning scoring systems allow early recognition of the deteriorating surgical patient? Critical Care Medicine 35, 402-409.

Donizetti Trevisan, D., Tresoldi Minzon, D., Valeriano Testi, C., Amorim Ramos. N., Valentim Carmona, E., \& Maria Silva, E. (2013). Education of nurses: Detachment 
between undergraduation courses and professional practices. Ciencia, Cuidado e Saude 12, 331-337.

Duke, M., Botti, M., \& Hunter, S. (2012). Effectiveness of pain management in hospital in the home programs. The Clinical Journal Of Pain 28, 187-194.

Eastern Health (2016). Medical Emergency Team (MET): clinical practice guideline.

Retrieved 1 September 2017 from

http://ehpolicies.eh.local:90/index.aspx?itemDetails=2147

Eastern Health (2013). Recognising and responding to clinical deterioration: clinical practice guideline. Retrieved 1 September 2017 from

http://ehpolicies.eh.local:90/index.aspx?itemDetails=2290\&xText=response to deterioration $\&$ xType $=$ ANY

Epworth Healtheare (2015). Epworth Hospital Standards. Retrieved 1 September 2017 from http://www.epworth.org.au/About-Us/Quality-of-Care/Hospital-

Standards/Pages/Standard-9.aspx

Farley, H., Zubrow, M. T., Gies, J., Kolm, P., Mascioli, S., Mahoney, D. D., \& Weintraub, W. S. (2010). Emergency Department Tachypnea Predicts Transfer to a Higher Level of Care in the First 24 hours After ED Admission. Academic Emergency Medicine 17, 718.

Felton, A., \& Royal, J. (2015). Skills for nursing practice: Development of clinical skills in pre-registration nurse education. Nurse Education in Practice 15, 38-43.

Fincham, J. E. (2008). Response rates and responsiveness for surveys, standards and the journal. American Journal of Pharmacuetical Education 72, 1-3

Gkantaras, I., Hahfoud, Z. R., Foreman, B., Thompson, D. R., Cannaby, A. M., Deshpande D. H., ...Gray, R. (2016) The effect of Nurse GraduaTeness on patient mortality: a cross sectional survey (the NuGaT study). Journal of Advanced Nursing, 11p.

IBM Corporation (2015). IBM Statistical package for the social sciences (SPSS), version 23 for Macintosh. Armonk, NY: IBM Corp.

Institue for Healthcare Improvement (2017). Utilization of the Rapid Response Team.

Retrieved 1 September 2017 from

http://www.ihi.org/resources/Pages/Measures/UtilizationoftheRapidResponseTeam.as px

Jones, D. (2014). The epidemiology of adult Rapid Response Team patients in Australia. Anaesthesia \& Intensive Care 42, 213-219. 
Kelly, M. A., Forber, J., Conlon, L., Roche, M., \& Stasa, H. (2014). Empowering the registered nurses of tomorrow: Students' perspectives of a simulation experience for recognising and managing a deteriorating patient. Nurse Education Today 34, 724729.

Khan, Y., Ostfeld, A. E., Lochner, C. M., Pierre, A., \& Arias, A. C. (2016). Monitoring of Vital Signs with Flexible and Wearable Medical Devices. Advanced Materials, 4373. Liaw SY, Scherpbier A, Klainin-Yobas P \& Rethans JJ (2011): A review of educational strategies to improve nurses' roles in recognizing and responding to deteriorating patients. International Nursing Review 58, 296-303.

Marques dos Santos, S. V., Esteves Ribeiro, M., Carnevalli Motta, A. L., de Almeida Silva, L. J., Rodrigues Resck, Z. M., \& de Souza Terra, F. (2016). Building Knowledge in Nursing: A reflective theoretical and methodological approach for nurses training. Journal of Nursing UFPE / Revista de Enfermagem UFPE 10, 172-178.

Monash Health (2015). Deteriorating patient recognition and management policy. Monash Health. Melbourne, VIC.

Morgan, S. N., \& Georges, J. M. (2015). Refocusing a Nursing Lens Distorted by Perfection: The Call for a Mid-range Theory. Journal of Theory Construction \& Testing 19, 2632.

National Institute for Health and Care Excellence (2017). Retrieved 1 September 2017 from https://www.nice.org.uk/standards-and-indicators

NHS England (2017). Urgent and ermergency care channel shift model. Retrieved 1 Seoptember 2017 from https://www.england.nhs.uk/euc-channel-shift/

Nursing and Midwifery Board of Australia (2015). Context of practice for registered nurses and midwives. Retrieved 1 September 2017 from http://www.nursingmidwiferyboard.gov.au/Codes-GuidelinesStatements/FAQ/Context-of-practice-for-registered-nurses-and-midwives.aspx Owen, J. A., Brasher, V. L., Littlewood, K. E., Wright, E., Childress, R. M., \& Thomas, S. (2014). Designing and evaluating an effective theory-based continuing interprofessional education program to improve sepsis care by enhancing healthcare team collaboration. Journal of Interprofessional Care 28, 212-217.

Parahoo, K. (2006). Nursing research : principles, process and issues (2nd ed.). Basingstoke, UK: Palgrave Macmillan. 
Polit, D. F., \& Beck, C. T. (2012). Nursing research : generating and assessing evidence for nursing practice (9th ed.). Philadelphia : Wolters Kluwer Health/Lippincott Williams \& Wilkins..

Purser, L., Warfield, K., \& Richardson, C. (2014). Making Pain Visible: An Audit and Review of Documentation to Improve the Use of Pain Assessment by Implementing Pain as the Fifth Vital Sign. Pain Management Nursing 15, 137-142.

Rahman, H. A., Jarrar, M., \& Don, M. S. (2015). Nurse Level of Education, Quality of Care and Patient Safety in the Medical and Surgical Wards in Malaysian Private Hospitals: A Cross-Sectional Study. Global Journal of Health Science 7, 331-337.

Saunders, M. (2016). Developing voluntary standards for district nurse education and practice. British Journal of Community Nursing 21, 240-245.

Schwab, P. (1994). The hospital in the home. Lamp 51, 21-21.

Shatkar, V., Alade, M., \& Amalesh, T. (2014). Surgical Readmissions: Causes And Cost Implications. Internet Journal of Surgery 31, 1-1.

Table 1. Setting details

\begin{tabular}{ccccc}
\hline Site & Employees & Facilities & Total beds & HITH - virtual beds \\
\hline Health Service A & $>10,000$ & 40 & 2170 & 103 \\
Health Service B & $>8,000$ & 50 & 1456 & 60 \\
Health Service C & $>7,000$ & 10 & 1200 & 25 \\
\hline
\end{tabular}

Table 2. Summary of scenario content

\section{Scenario}

A 63-year-old female with lower leg cellulitis who lives with her husband. She has been receiving home-based care for two days and is receiving intravenous antibiotic therapy twice per day. A 34-year-old female with pneumonia living with her husband and three young children, who has just spent four days in hospital with pneumonia, and has been receiving home-based care for two days. She is currently receiving daily intravenous antibiotic therapy. An 85-year-old male with bacteraemia who has just spent two weeks in hospital. The plan is for six weeks of intravenous antibiotics daily by continuous infusion and he has been receiving this treatment at home for four days.

4 A 75-year-old male with recurrent pulmonary emboli and is taking lifelong warfarin. He has been 
referred to HITH for bridge anticoagulation with subcutaneous enoxaparin pre and post investigative bronchoscopy for a lung lesion.

A 70-year-old male who spent time in the Intensive Care Unit for septic shock secondary to a foot abscess. Once well enough, he was referred to HITH for a total of 6 weeks intravenous antibiotic therapy.

A 20-year-old male, living at home with cellulitis of his right arm after sustaining several

6 mosquito bites on a recent holiday overseas to Thailand. He is being treated with intravenous antibiotic therapy twice daily.

A 47-year-old male who has had recent surgery for an abdominal hernia. Post operatively the

7 wound became broken down and infected, requiring debridement and intravenous antibiotic therapy via a peripherally inserted central catheter (PICC) and Computerized Ambulatory Delivery Device (CADD) pump.

8 An 18-year-old female who has had surgery for a large peri-anal abscess that now requires negative pressure wound dressings post debridement.

A 65-year-old female who has been diagnosed with a left lower leg deep vein thrombosis (DVT).

9

She has been prescribed oral warfarin for the next three months, and is receiving bridging subcutaneous enoxaparin until her international normalized ratio (INR) is within a therapeutic range.

A 56-year-old female who has had a right wide local excision and biopsy for cancer of the breast. She has a drain tube in situ just beneath the wound, which is for daily site assessment and measurement.
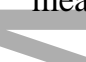

\section{Table 3. Participant characteristics}

\begin{tabular}{|c|c|c|}
\hline Classification & $\mathrm{n}$ & $\%$ \\
\hline Registered Nurse - Grade 3B & 34 & 72.3 \\
\hline Registered Nurse - Grade 2 & 0 & 0 \\
\hline Associate Nurse Unit Manager / Nurse Unit Manager & 12 & 25.5 \\
\hline 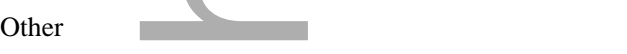 & 1 & 2.1 \\
\hline $\begin{array}{ll} & \text { Experience } \\
\end{array}$ & Median & IQR \\
\hline Full time equivalent hours per fortnight (FTE) & 56 & $32-64$ \\
\hline Years as a registered nurse & 20 & $15-28$ \\
\hline Years practicing in home-based care settings & 4 & 3-9.25 \\
\hline $\begin{array}{l}\text { Years practicing in home-based care settings } \\
\text { in your current workplace }\end{array}$ & 4 & $3-6.50$ \\
\hline Qualifications* & $\mathrm{n}$ & $\%$ \\
\hline Certificate of Nursing (hospital trained RN) & 12 & 25.5 \\
\hline Diploma of Nursing (DN) & 9 & 19.1 \\
\hline Bachelor of Nursing (BN) & 31 & 66.0 \\
\hline
\end{tabular}




\begin{tabular}{|c|c|c|}
\hline Education & $\mathrm{n}$ & $\%$ \\
\hline Hospital Post-Graduate Certificate & 5 & 10.6 \\
\hline Graduate Certificate & 6 & 12.8 \\
\hline Graduate Diploma & 11 & 23.4 \\
\hline Master's Degree & 0 & 0 \\
\hline Doctoral Degree (e.g. PhD) & 0 & 0 \\
\hline Other & 2 & 4.3 \\
\hline No response & 23 & 48.9 \\
\hline
\end{tabular}

*Note: participants were able to indicate more than one response

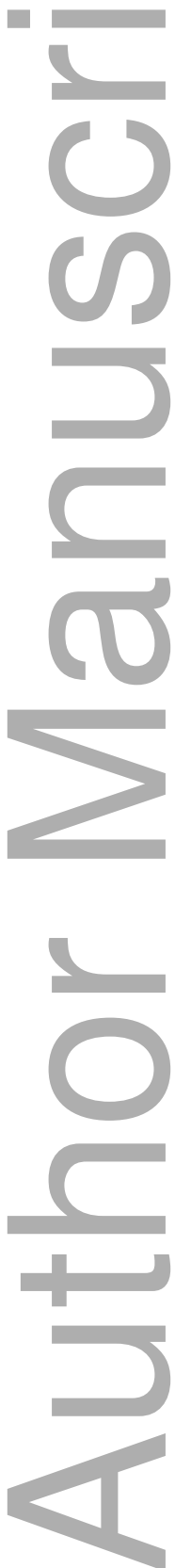


Table 4. Summary of clinical cues rated as very important indicators of deterioration

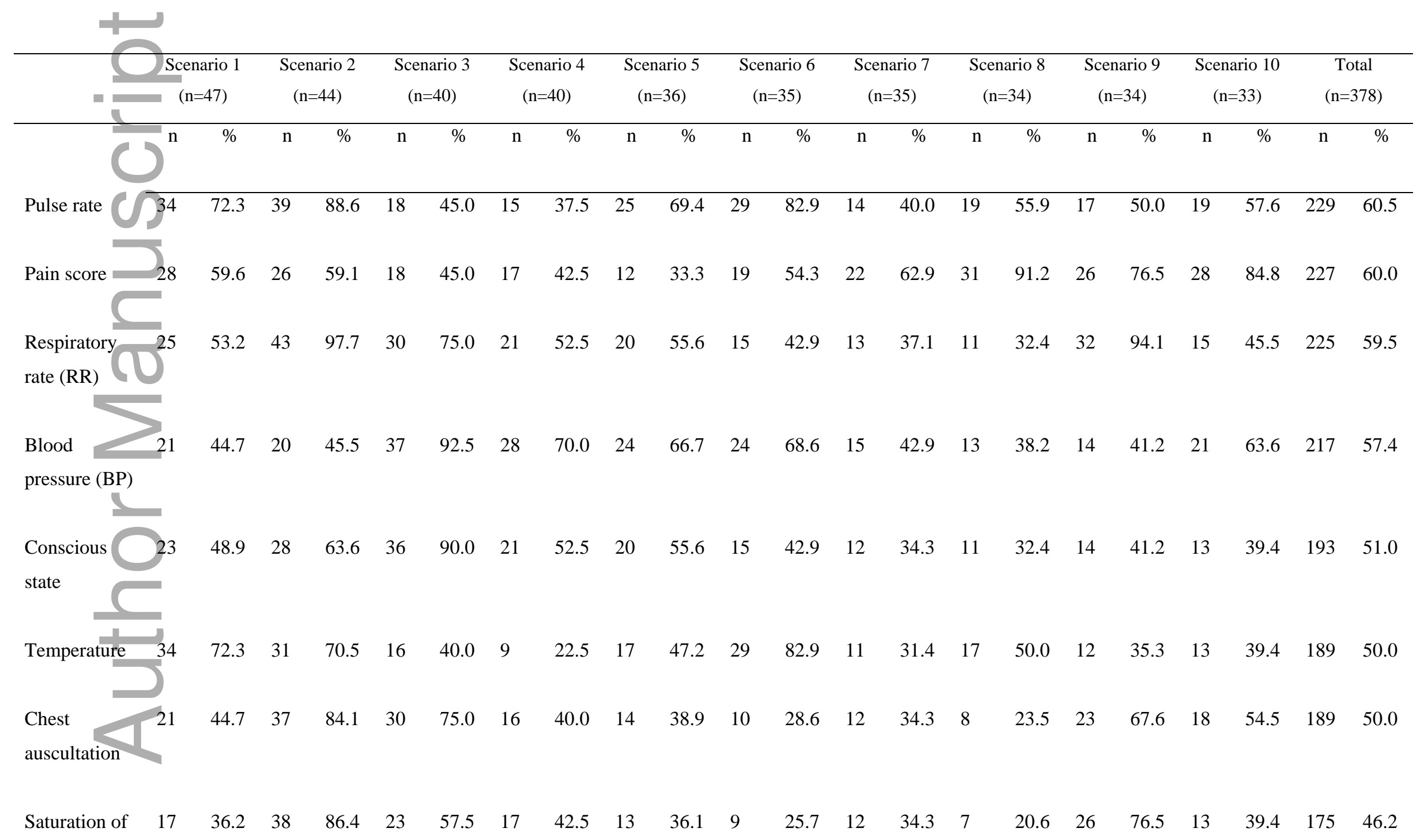

This article is protected by copyright. All rights reserved 
Oxygen

(SpO2)

$\begin{array}{lllllllllllllllllllllll}\text { Pulse rhythm } & 24 & 51.1 & 19 & 43.2 & 18 & 45.0 & 16 & 40.0 & 21 & 58.3 & 19 & 54.3 & 14 & 40.0 & 12 & 35.3 & 13 & 38.2 & 12 & 36.4 & 168 & 44.4\end{array}$

10

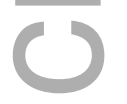

Table 5. Responses to clinical deterioration

\begin{tabular}{|c|c|c|c|c|c|c|c|c|c|c|c|c|c|c|c|c|c|c|c|c|c|c|}
\hline & \multicolumn{2}{|c|}{$\begin{array}{l}\text { Scenario } 1 \\
\qquad(\mathrm{n}=47)\end{array}$} & \multicolumn{2}{|c|}{$\begin{array}{c}\text { Scenario } 2 \\
\quad(\mathrm{n}=44)\end{array}$} & \multicolumn{2}{|c|}{$\begin{array}{c}\text { Scenario } 3 \\
\quad(\mathrm{n}=40)\end{array}$} & \multicolumn{2}{|c|}{$\begin{array}{c}\text { Scenario } 4 \\
\quad(\mathrm{n}=40)\end{array}$} & \multicolumn{2}{|c|}{$\begin{array}{c}\text { Scenario } 5 \\
\quad(\mathrm{n}=36)\end{array}$} & \multicolumn{2}{|c|}{$\begin{array}{c}\text { Scenario } 6 \\
\quad(\mathrm{n}=35)\end{array}$} & \multicolumn{2}{|c|}{$\begin{array}{c}\text { Scenario } 7 \\
(\mathrm{n}=35)\end{array}$} & \multicolumn{2}{|c|}{$\begin{array}{c}\text { Scenario } 8 \\
(\mathrm{n}=34)\end{array}$} & \multicolumn{2}{|c|}{$\begin{array}{c}\text { Scenario } 9 \\
\quad(\mathrm{n}=34)\end{array}$} & \multicolumn{2}{|c|}{$\begin{array}{l}\text { Scenario } 10 \\
\qquad(\mathrm{n}=33)\end{array}$} & \multicolumn{2}{|c|}{$\begin{array}{c}\text { Total } \\
(\mathrm{n}=378)\end{array}$} \\
\hline & $\mathrm{n}$ & $\%$ & $\mathrm{n}$ & $\%$ & $\mathrm{n}$ & $\%$ & $\mathrm{n}$ & $\%$ & $\mathrm{n}$ & $\%$ & $\mathrm{n}$ & $\%$ & $\mathrm{n}$ & $\%$ & $\mathrm{n}$ & $\%$ & $\mathrm{n}$ & $\%$ & $\mathrm{n}$ & $\%$ & $\mathrm{n}$ & $\%$ \\
\hline $\begin{array}{l}\text { Consult with } \\
\text { treating } \\
\text { medical team } \\
\text { by phone }\end{array}$ & 24 & 51.1 & 22 & 50.0 & 4 & 10.0 & 16 & 40.0 & 25 & 69.4 & 14 & 40.0 & 5 & 10.6 & 17 & 50.0 & 5 & 14.7 & 15 & 45.5 & 133 & 35.1 \\
\hline $\begin{array}{l}\text { Urgent face-to- } \\
\text { face medical } \\
\text { review in clinic } \\
\text { (in-hours) }\end{array}$ & 4 & 8.5 & 13 & 29.5 & 20 & 50.0 & 4 & 10.0 & 6 & 16.7 & 13 & 37.1 & 16 & 45.7 & 7 & 20.6 & 8 & 23.5 & 7 & 21.2 & 98 & 25.9 \\
\hline Other: & 6 & 12.8 & 4 & 9.1 & 3 & 7.5 & 2 & 5.0 & 0 & 0 & 5 & 14.3 & 5 & 14.3 & 4 & 11.8 & 5 & 14.7 & 1 & 2.1 & 35 & 9.2 \\
\hline $\begin{array}{l}\text { Urgent face-to- } \\
\text { face medical } \\
\text { review in ED } \\
\text { (out-of-hours) }\end{array}$ & 0 & 0 & 4 & 9.1 & 2 & 5.0 & 0 & 0 & 1 & 2.8 & 1 & 2.9 & 9 & 25.7 & 1 & 2.9 & 3 & 8.8 & 8 & 24.2 & 29 & 7.7 \\
\hline $\begin{array}{l}\text { Call an } \\
\text { ambulance }\end{array}$ & 0 & 0 & 1 & 2.3 & 11 & 23.4 & 0 & 0 & 0 & 0 & 1 & 2.9 & 0 & 0 & 0 & 0 & 12 & 35.3 & 2 & 6.1 & 27 & 7.1 \\
\hline
\end{tabular}

This article is protected by copyright. All rights reserved 


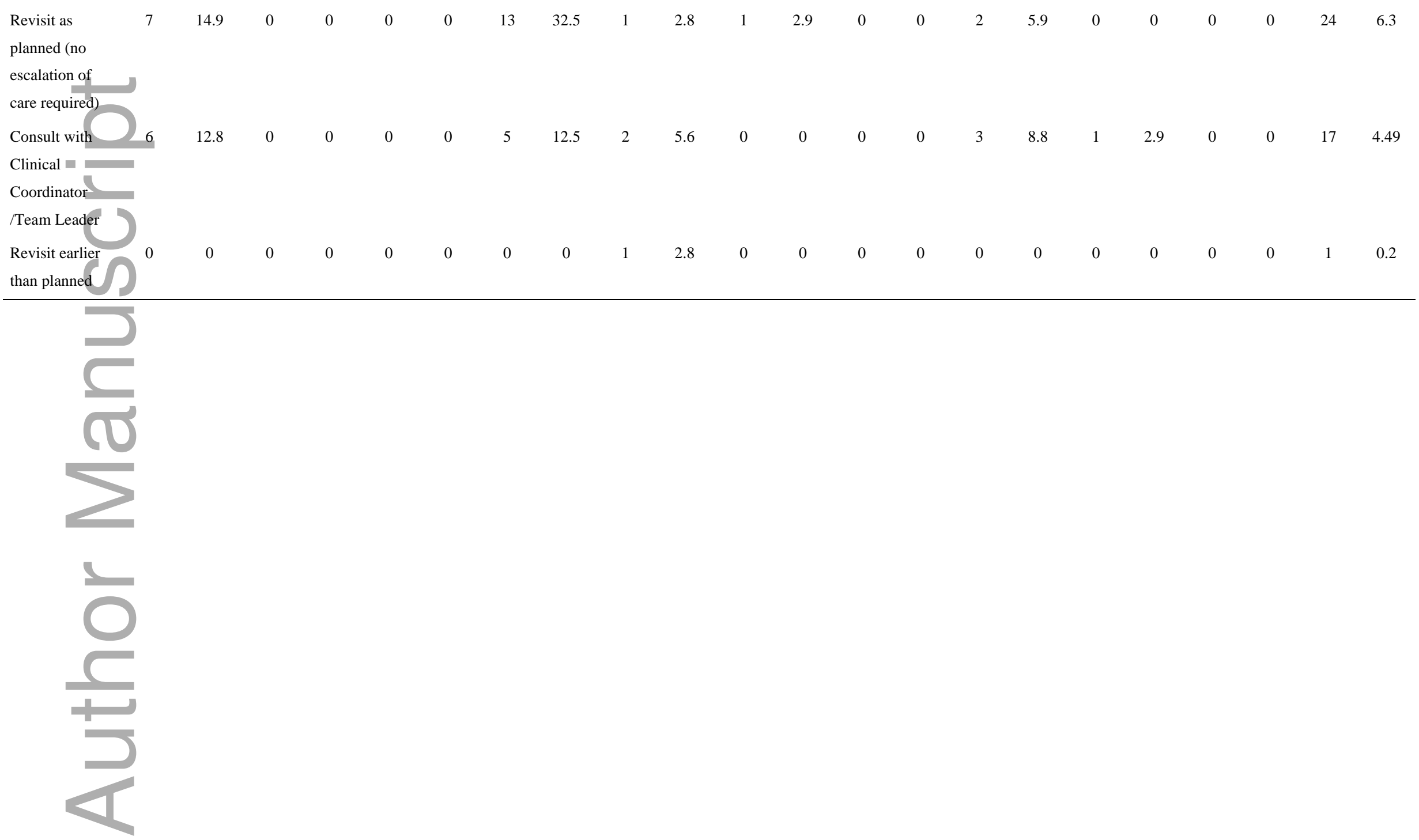

This article is protected by copyright. All rights reserved 
Table 6. Identified themes and participant comments

Scenario 1

Identified Themes

Participant Comments

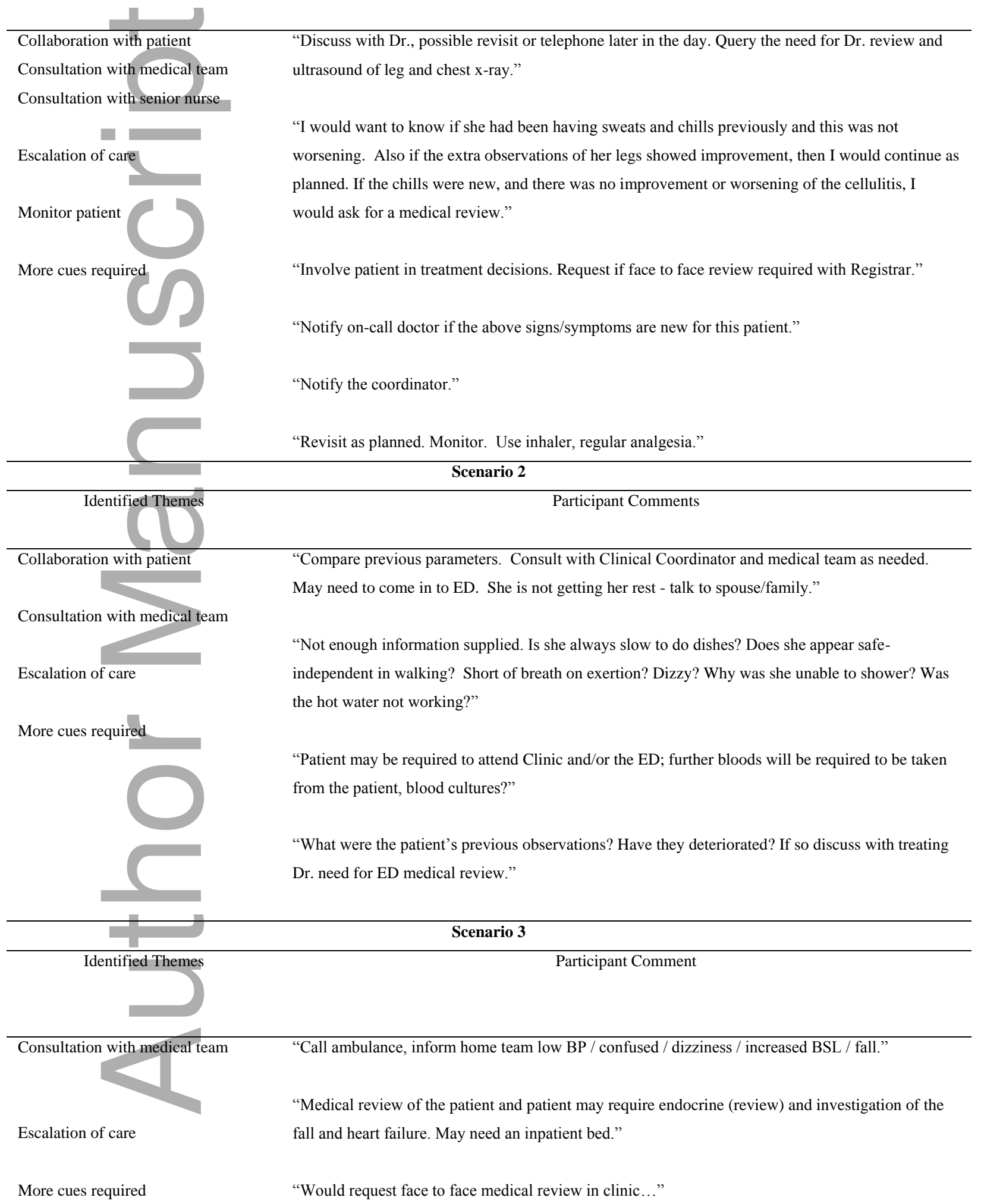




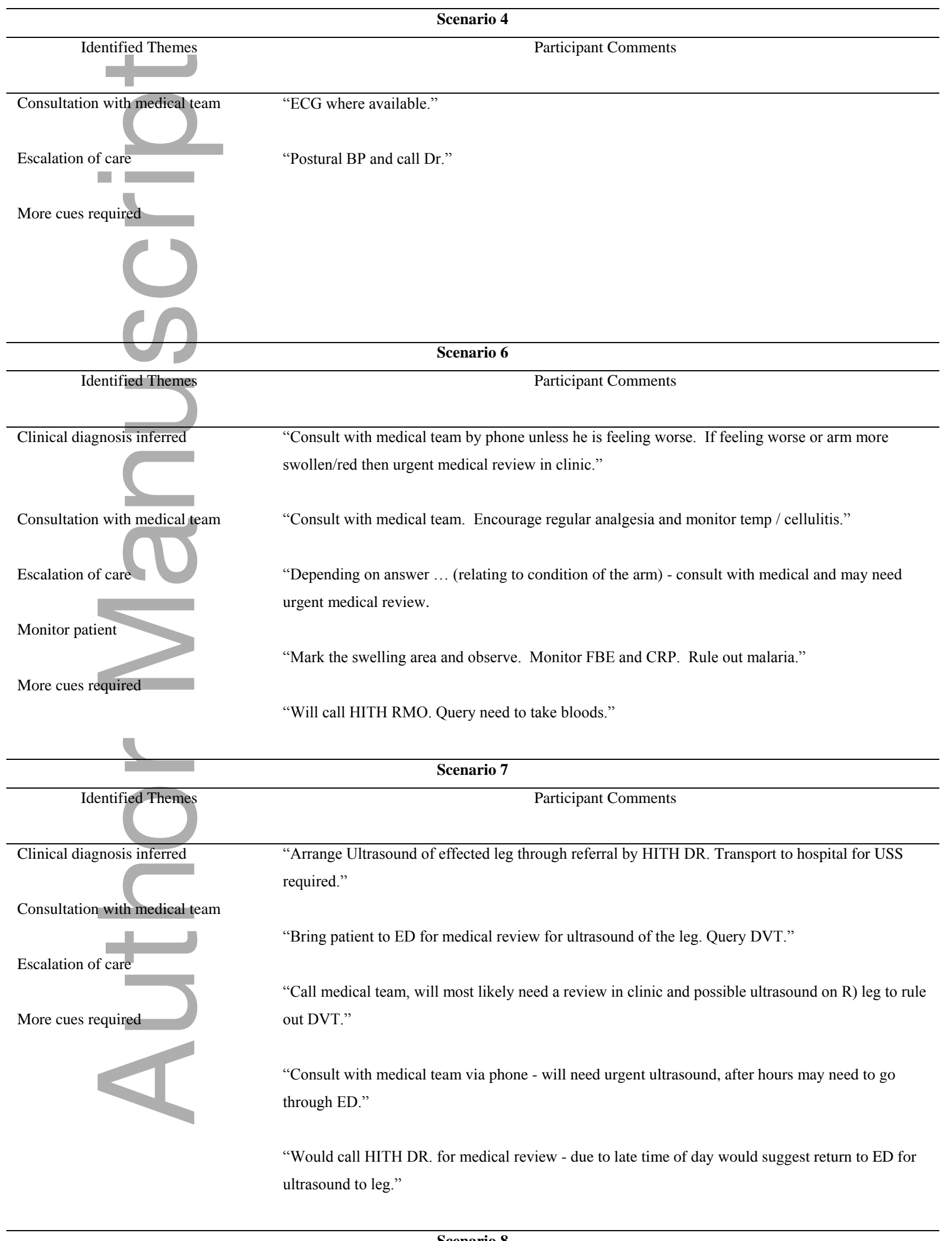




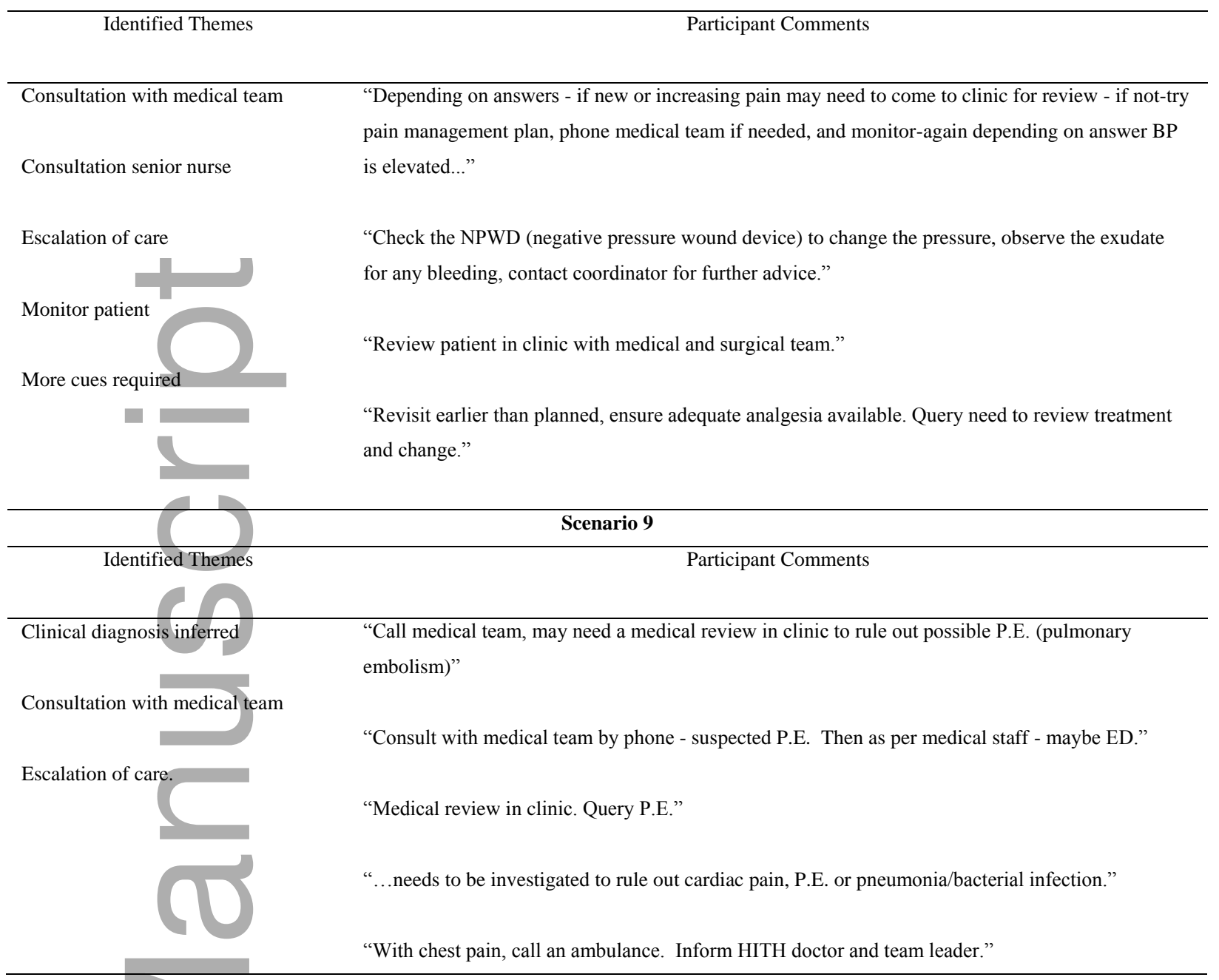

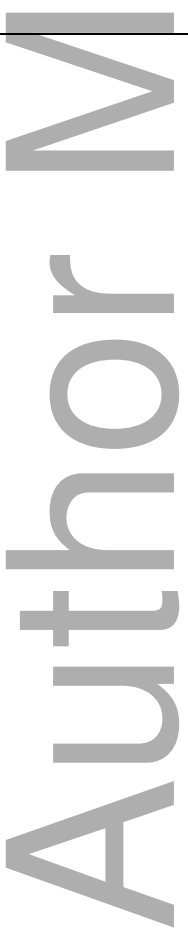




\section{University Library}

\section{- M M N E R VA A gateway to Melbourne's research publications}

Minerva Access is the Institutional Repository of The University of Melbourne

Author/s:

Gray, E;Currey, J;Considine, J

Title:

Hospital in the Home nurses' recognition and response to clinical deterioration.

Date:

2018-05

Citation:

Gray, E., Currey, J. \& Considine, J. (2018). Hospital in the Home nurses' recognition and response to clinical deterioration.. J Clin Nurs, 27 (9-10), pp.2152-2160. https:// doi.org/10.1111/jocn.14076.

Persistent Link:

http://hdl.handle.net/11343/293987 